Neurosurg Focus 7 (4):Article 9, 1999

\title{
Seven-year clinical experience with the Codman Hakim programmable valve: a retrospective study of 583 patients
}

\section{Göran Zemack, M.D., and Bertil Romner, M.D., Ph.D.}

Department of Neurosurgery, Division of Neurological Sciences, Lund University Hospital, Lund, Sweden

A retrospective study was undertaken to assess the value of the Codman Hakim programmable valve in the treatment of 583 patients (421 adults and 162 children) with hydrocephalus of various causes (379), normal-pressure hydrocephalus (NPH) (174), an arachnoidal cyst (14), and pseudotumor cerebri (16). In all patients the programmable valve was implanted (the valve can be noninvasively adjusted to settings in the range of $30-200 \mathrm{~mm} \mathrm{H}_{2} \mathrm{O}$ ). In $73 \%$ of the cases this was their first shunt implantation. Ninety-two percent of the shunts drained to the peritoneal cavity and $8 \%$ to the atrium. In $42 \%$ of the cases valve pressure adjustment was required at least once (mean number of adjustments 1.2, maximum 23).

The authors present reprogramming statistics, and strategies for reprogramming are discussed. In $65 \%$ of the cases in which pressure adjustments were required, reprogrammings improved the patients' clinical status. The overall infection rate was $8.5 \%$ (56 of 660 valve implantations). Valve malfunction, blockage, or reprogramming difficulty occurred in 17 cases, and nontraumatic subdural fluid collections were demonstrated in 30 cases ( 13 of which were treated by valve pressure reprogramming alone). Of the patients undergoing first-time shunt placement, $21.5 \%$ eventually underwent shunt revision at least once, and a total of 318 revisions were performed during the 7-year follow-up period. At follow up, $97 \%$ of children and $90 \%$ of adults had improved.

In conclusion, catheter-related complications and shunt-related infections were the main reasons for revision and the major cause of shunt failure. Few incidents of valve malfunction were observed. The Hakim Codman programmable valve is of value in the treatment of hydrocephalus of all causes, especially in the treatment of patients with NPH, pseudotumor cerebri, arachnoidal cyst, aqueductal stenosis, traumatic hydrocephalus, and intraventricular hemorrhage.

Key Words * hydrocephalus * pressure-adjustable valve * cerebrospinal fluid * valve adjustment * Codman Hakim programmable valve

Valve-regulated cerebrospinal fluid (CSF) shunt systems are used in the treatment of hydrocephalus, intracranial cysts, and pseudotumor cerebri. When selecting the type of valve to implant, several aspects must be considered. One of these aspects is the opening pressure, the pressure at which the valve opens 
and begins to drain CSF.

Preoperative selection of the most suitable opening pressure for any individual patient is difficult because it often needs to be adjusted during the postoperative period.[2,4,11,13,14,18,20-23,25,31,32,35,36] When using a valve with a nonadjustable opening pressure, postoperative alterations to that opening pressure can only be accomplished by exchanging the valve, which entails a reoperation.

In 1973 Hakim[13] proposed the use of a shunt system with an adjustable-valve opening pressure and later suggested that the valve opening pressure was the most important factor in determining CSF drainage.[12] A programmable valve allows the surgeon to adjust the opening pressure setting noninvasively in accordance with clinical or radiological findings in the postoperative period without having to perform reoperation to make pressure adjustments.[4,16,20,21,27-29,31-33]

The Codman Hakim programmable valve, formerly known as the Codman Medos programmable valve (Codman, Johnson \& Johnson Co., Raynham, MA), has been used at the Department of Neurosurgery at Lund University Hospital since 1992. We present data obtained from a retrospective study to evaluate the first 7 years of clinical experience with the use of this valve.

\section{CLINICAL MATERIAL AND METHODS}

\section{Codman Hakim Programmable Valve}

In the case of this particular valve, the alternating polarity of the magnetic field surrounding the valve allows transcutaneous adjustment of the valve's opening pressure setting in a range from 30 to $200 \mathrm{~mm}$ $\mathrm{H}_{2} \mathrm{O}$ in steps of $10 \mathrm{~mm} \mathrm{H}_{2} \mathrm{O}$. This setting can be confirmed by plain skull radiography or fluoroscopy. The valve is available with or without a prechamber.

\section{Patient Population}

Six hundred sixty programmable valves were implanted in 583 consecutive patients between the beginning of 1992 and the end of 1998. Patient age at implantation ranged from prematurely born infants to 89 years (mean age 42 years, median 50 years), as shown in Fig. 1. 


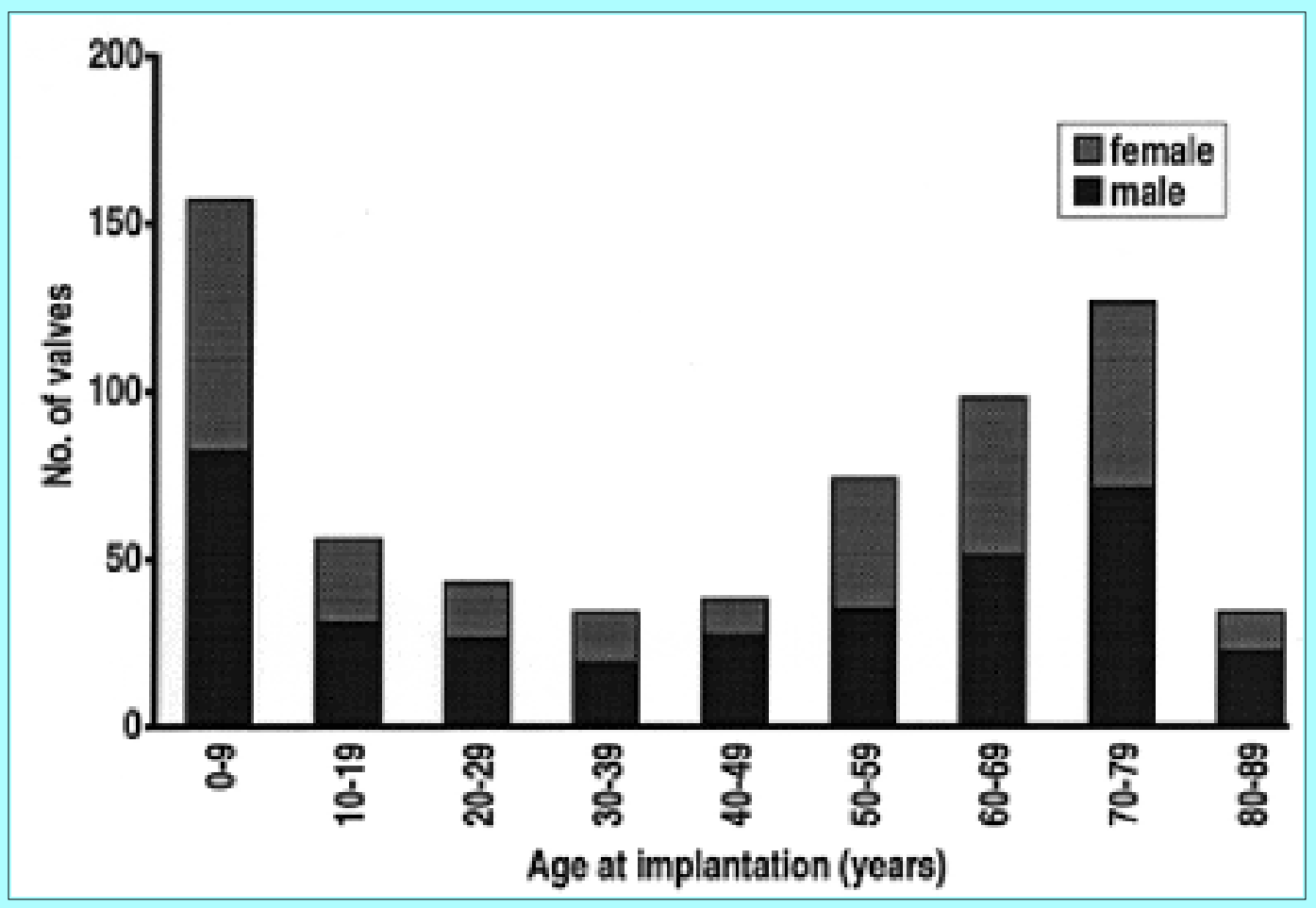

Fig. 1. Bar graph showing the distribution of patient age at the time of programmable valve implantation.

Overall $27.8 \%$ ( 162 cases) were children younger than 18 years of age (mean age 4.5 years, median 0.5 years), and $72.2 \%$ ( 421 cases) were adults (mean age 58.9 years, median 63.6 years). Of the 203 shunt systems implanted in children, 115 were in children younger than 2 years of age (including 14 patients with a gestational age younger than 38 weeks at the time of implantation). Four hundred fifty-seven valves were implanted in adults. The underlying reasons for requiring a shunt valve system are listed in Table 1. 


\begin{tabular}{|c|c|c|c|}
\hline SUMMMRY OF CONDITIONS & $\begin{array}{l}\text { TABLE } 1 \\
\text { TIENTS REQ } \\
\text { 'LANTATIONS }\end{array}$ & 660 PROGF & LE YALYE \\
\hline \multirow[b]{2}{*}{ Condition } & \multicolumn{3}{|c|}{ No. of Patients (no. of walves) } \\
\hline & Children & Adults & Al Patients \\
\hline$m$ yelom eningocele & $33(35)$ & $10(12)$ & $43(47)$ \\
\hline Dandy-'walker cyst & $8(9)$ & $2(2)$ & $10(11)$ \\
\hline $\begin{array}{l}\text { congenital, miscellane ous } \\
\text { aqueductal stenosis }\end{array}$ & $\begin{array}{l}14(17) \\
19(21)\end{array}$ & $24(27)$ & $\begin{array}{l}16(19) \\
43(48)\end{array}$ \\
\hline tumor & 19 (21) & $78(79)$ & $97(100)$ \\
\hline acquired, miscellane ous & $11(12)$ & $13(13)$ & 24 (25) \\
\hline infection, miscellaneous & $7(11)$ & $4(4)$ & $11(15)$ \\
\hline meningits & $5(9)$ & 11 (14) & $16(23)$ \\
\hline \multirow{2}{*}{\multicolumn{4}{|c|}{ intracranial hem orrhage }} \\
\hline & & & \\
\hline in traventricular & $29(43)$ & - & $29(43)$ \\
\hline subarachnoid & & $40(43)$ & $40(43)$ \\
\hline miscellaneous & $5(11)$ & 12 (12) & 17 (23) \\
\hline \multicolumn{4}{|l|}{$\mathrm{NPH}$} \\
\hline idiopathic & - & $122(131)$ & $122(131)$ \\
\hline subarachnoid hemormage & - & $30(34)$ & $30(34)$ \\
\hline meningitis & - & 2 (2) & 2 (2) \\
\hline trauma & - & 20 (23) & 20 (23) \\
\hline arachnoidal cyst & $1(1)$ & $13(15)$ & $14(16)$ \\
\hline pseudotumor ceretri & $3(3)$ & 13 (14) & 16 (17) \\
\hline unknown & $5(6)$ & $4(4)$ & $9(10)$ \\
\hline total & $162(203)$ & $421(457)$ & $583(660)$ \\
\hline
\end{tabular}

Overall, $483(73.2 \%)$ of the 660 valves were used in first-time shunt implantation procedures (61\% in children and $79 \%$ in adults). A Codman Hakim programmable valve was used in a first-time shunt implantation in $483(82.8 \%)$ of 583 patients. A Codman Hakim programmable valve was replaced with a new Codman Hakim programmable valve in 77 cases. Eleven patients received more than two Codman Hakim programmable valves.

\section{Valve Pressure Programming}

Opening Pressure at Implantation. The opening pressure settings at implantation were decided based on the patient's age, diagnosis, duration of the underlying disease, and the size of the ventricles or cyst as demonstrated on computerized tomography (CT), magnetic resonance (MR) imaging, or ultrasonography. For patients with normal-pressure hydrocephalus (NPH) the opening pressure setting was also based on a tap test and on the curve profile, amplitude, and opening pressure of a lumbar infusion test. This initial programming was performed while the valve was still placed in its sterile blister package, ensuring a proper positioning of the programming unit's transmitter.

Valve Pressure Reprogramming. Reprogrammings adjustments that were made to correct accidental resettings (due to unintentional magnetic interference) were disregarded when calculating percentages, averages, or the number of reprogrammings per valve or per group of patients.

Reprogramming adjustments were assessed as to their effect on patients' symptoms, signs or radiological findings.

\section{Follow-Up Review}


Outcome was based on an assessment at the patient's last contact with our department, which included patients who died during the follow-up period. Only patients who underwent follow-up review of at least 3 months were evaluated in this study. The average time until outcome assessment was 25 months for all patients (median 19 months, maximum 80 months). For children, the average time to outcome was 32 months (median 29 months, maximum 80 months) and for adults 22 months (median 16 months, maximum 78 months). Outcome was determined by the effect of treatment on symptoms, signs, and radiological findings of the raised intracranial pressure, not comorbidity, and it was graded as "excellent" (a clear improvement with only minor residual symptoms or signs and return to independent living); "good" (improvement but moderate residual symptoms or signs); "unchanged;" and "worse."

\section{RESULTS}

\section{Shunt Implantation}

Ninety-two percent (607) of the distal catheters (96\% in children, $90 \%$ in adults) were placed in the peritoneal cavity and $8 \%$ (53 cases) in the atrium of the heart (3\% in children and $10 \%$ in adults). Twelve $(1.8 \%)$ of the shunts drained a cyst (1\% in children, $2.2 \%$ in adults) and $14(2.1 \%)$ drained both a cyst and a ventricle (5.4\% in children, $0.6 \%$ in adults). One child and two adults received lumboperitoneal shunts.

To enable retroauricular positioning of the valve, the prechamber was cut off in 29 cases (19 times in children and 10 times in adults). One siphon-reducing device (Codman Siphon-Guard; Codman Medos, Le Locle, Switzerland) was implanted in one adult patient.

\section{Valve Pressure Programming}

Opening Pressure at Implantation. The selected average opening pressures at implantation are presented for each age group in Fig. 2 upper and for the different diagnoses in Fig. 2 lower. 

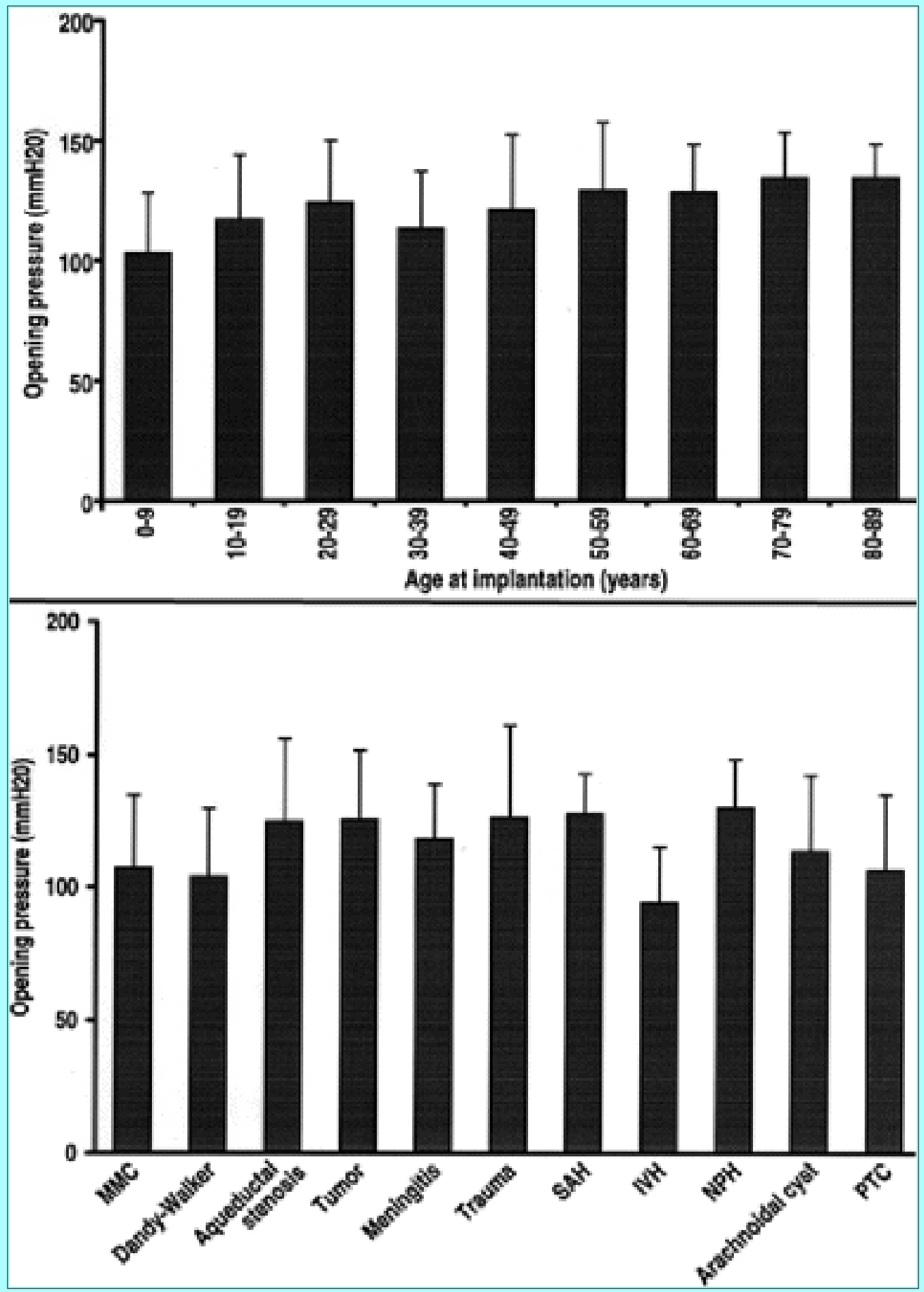

Fig. 2. Bar graphs. Upper: Average opening pressure according to different age groups at the time of implantation. Lower: Average opening pressure at the time of implantation, grouped by diagnosis. Error bars represent standard deviations. $\mathrm{MMC}=$ myelomeningocele; IVH = intraventricular hemorrhage; $\mathrm{PTC}=$ pseudotumor cerebri; $\mathrm{SAH}=$ subarachnoid hemorrhage .

Reprogramming. Overall 706 reprogramming adjustments were performed (average of 1.2 reprogrammings per patient). The capability to adjust the opening pressure was used at least once in $42.4 \%$ (247 cases) of all patients (in 38.7\% [163] of adults and in 51.9\% [84] of children), but in 45.7\% (113) of these patients their valve was reprogrammed only once; the maximum number of reprogramming adjustments in one patient was 23 (Table 2). 


\begin{tabular}{|c|c|c|c|}
\hline \multicolumn{4}{|c|}{$\begin{array}{c}\text { TABLE } 2 \\
\text { NuMBER OF RE PROGRAMMING AD USTMENTS REQURED PER PATIENT IN THOSE WHOSE } \\
\text { YALYES WERE RE PROGRAMMED AT LEAST ONCE }\end{array}$} \\
\hline \multirow{2}{*}{$\begin{array}{c}\text { No. of } \\
\text { Reprogrammings } \\
\text { Per Patient }\end{array}$} & \multicolumn{3}{|c|}{ Number of patierts } \\
\hline & Children & Adults & Al Patients \\
\hline 1 & $36(42.9 \%)$ & $78(47.9 \%)$ & $114(46.2 \%)$ \\
\hline 2 & $24(28.6 \%)$ & $43(26.4 \%)$ & $67(27.1 \%)$ \\
\hline 3 & $9(10.7 \%)$ & $19(11.7 \%)$ & $28(11.4 \%)$ \\
\hline 4 & $7(8.4 \%)$ & $9(5.5 \%)$ & $16(6.5 \%)$ \\
\hline 5 & $2(2.3 \%)$ & $3(1.8 \%)$ & $5(2.0 \%)$ \\
\hline 6 & $1(1.2 \%)$ & $6(3.7 \%)$ & $7(2.8 \%)$ \\
\hline 7 & $2(2.3 \%)$ & $1(0.6 \%)$ & $3(1.2 \%)$ \\
\hline 8 & $1(1.2 \%)$ & - & $1(0.4 \%)$ \\
\hline 9 & - & $1(0.6 \%)$ & $1(0.4 \%)$ \\
\hline 12 & - & $1(0.6 \%)$ & $1(0.4 \%)$ \\
\hline 13 & $1(1.2 \%)$ & $1(0.6 \%)$ & $2(0.8 \%)$ \\
\hline 16 & $1(1.2 \%)$ & - & $1(0.4 \%)$ \\
\hline 23 & - & $1(0.6 \%)$ & $1(0.4 \%)$ \\
\hline total & 84 & 163 & 247 \\
\hline
\end{tabular}

Reprogramming was required in $48 \%$ of patients whose initial programmable valve was implanted at shunt revision compared with $41.2 \%$ of those in whom the shunt was implanted for the first time. The percentage of patients whose valves were reprogrammed at least once is presented based on diagnosis group in Table 3.

\begin{tabular}{|lc|}
\hline \multicolumn{2}{|c|}{ TABLE 3 } \\
NUMBER OF PATIENTS IN WHOM YALV RE PROGRAMMING WAS \\
REQURED AT LEAST ONCE, GROU PED BV DIAGNOS S \\
\hline \hline \multicolumn{1}{|c|}{ Diagnosis } & No. of Patierts \\
\hline Dandy-inalker cyst & $7(70.0 \%)$ of 11 \\
in traventricular hemormage & $19(65.5 \%)$ of 29 \\
aqueductal stenosis & $27(62.8 \%)$ of 8 \\
arachnoidal cyst & $8(57.1 \%)$ of 14 \\
trauma & $12(50.0 \%)$ of 24 \\
NPH & $74(42.5 \%)$ of 174 \\
m yelom eningocele & $18(41.9 \%)$ of 43 \\
meningitis & $6(37.5 \%)$ of 16 \\
pseudotumor ceretri & $5(31.3 \%)$ of 16 \\
tumor & $30(30.9 \%)$ of 97 \\
subarachnoid hemormage & $10(33.3 \%)$ of 30 \\
\hline
\end{tabular}

The average number of times that the opening pressure was reprogrammed per patient (excluding reprogramming adjustments performed to correct a failed reprogramming) demonstrated a weak tendency toward fewer reprogramming adjustments performed with increasing patient age $(\mathrm{r}=0.134, \mathrm{p}=$ $0.0013)$. The average number of valve pressure adjustments performed per diagnosis group are shown in Fig. 3 upper. 

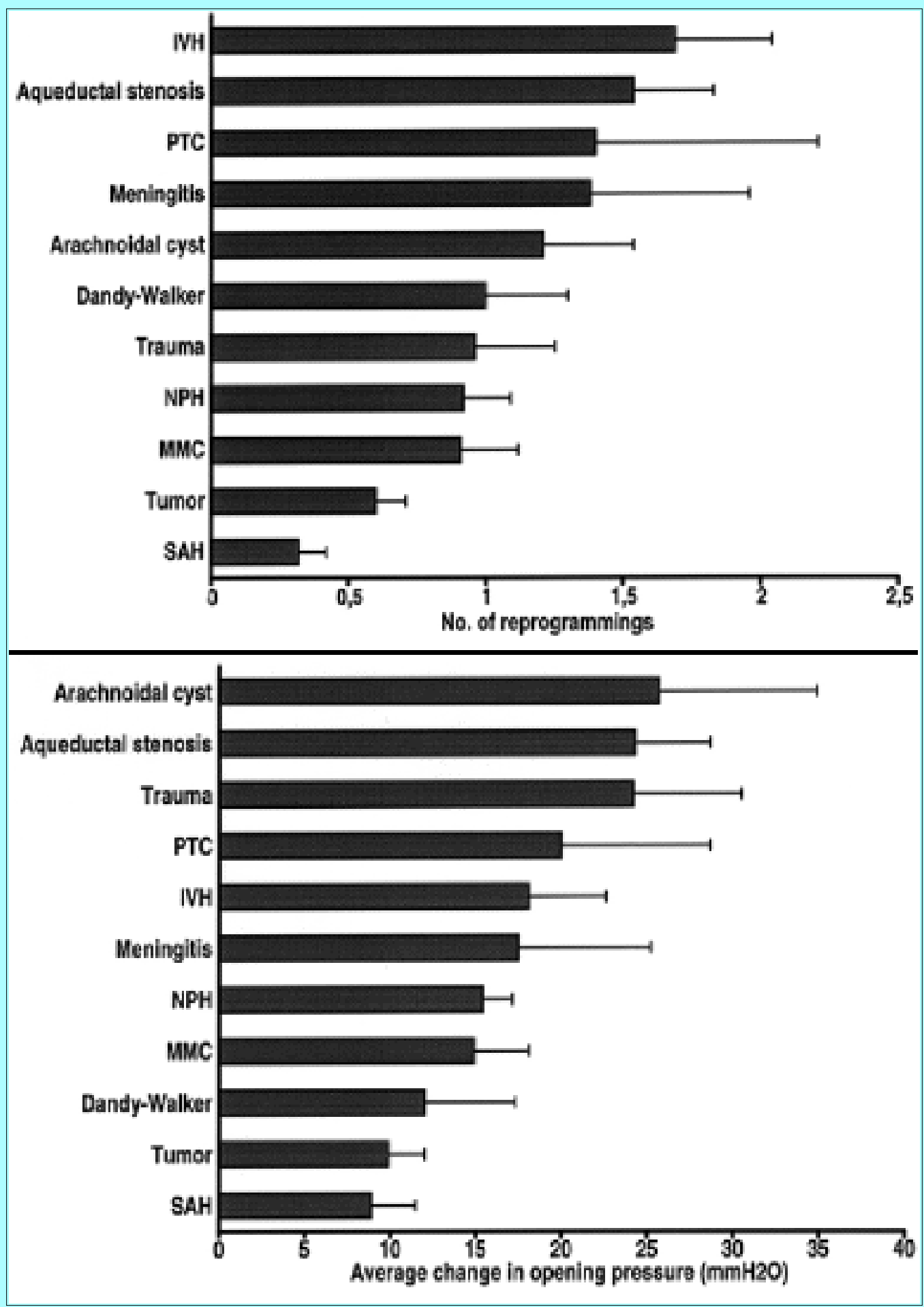

Fig. 3. Bar graphs. Upper: Average number of reprogramming adjustments made per patient, grouped by diagnosis. Lower: Average change in opening pressure (increase or decrease) at follow up compared with time of implantation. Error bars represent standard errors of the mean.

Analyis of data on the average change in opening pressure between implantation and follow up, (either increase or decrease) showed no correlation to age or significance between age groups. Significant differences were not demonstrated when comparing the diagnostic groups, but the averages do indicate how the magnitude of the change in opening pressure varied among groups (Fig. 3 lower).

Of the proximal catheters inserted in a cyst, the average difference in opening pressure between 
implantation and follow up was $-24.0 \mathrm{~mm} \mathrm{H}_{2} \mathrm{O}$ as compared with $1.7 \mathrm{~mm} \mathrm{H}_{2} \mathrm{O}$ for ventricular catheters. The average change in opening pressure setting per patient was $28 \mathrm{~mm} \mathrm{H}_{2} \mathrm{O}$ in the former group compared with $15.2 \mathrm{~mm} \mathrm{H}_{2} \mathrm{O}$ in the latter group.

A majority of pressure reprogrammings were performed within a few months of implantation, but some were undertaken as many as 6.6 years later (Fig. 4). The average time to the first reprogramming was 129 days (median 43 days). The magnitude of the individual reprogrammings was on average $35.2 \mathrm{~mm} \mathrm{H}_{2} \mathrm{O}$ in adults compared with $27.2 \mathrm{~mm} \mathrm{H}_{2} \mathrm{O}$ in children.

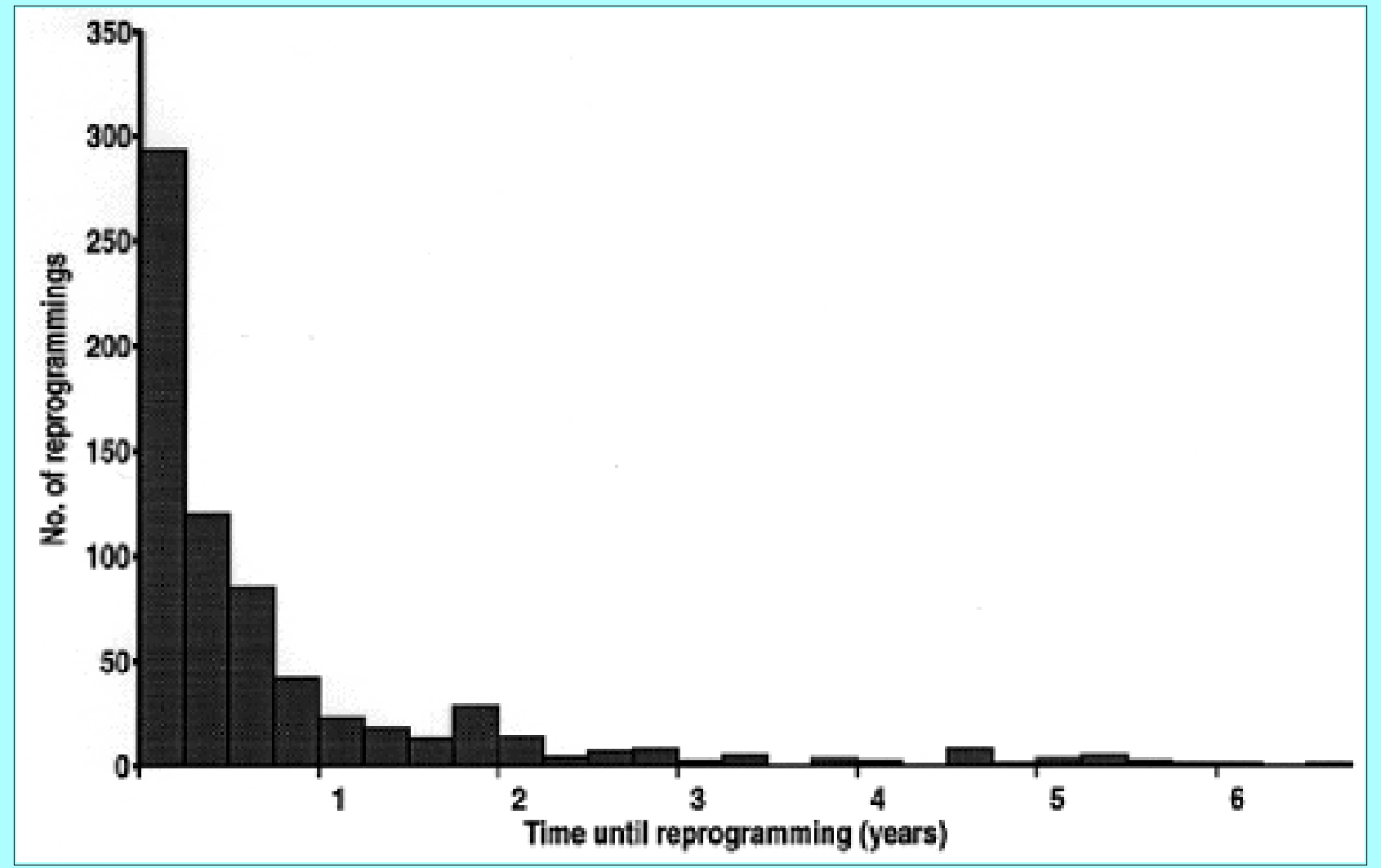

Fig. 4. Bar graph depicting the time after implantation at which reprogramming adjustments were performed. Most pressure adjustments were made during the 1st year after implantation. In selected cases reprogramming adjustments were made up to 6.6 years after insertion.

Reprogramming Failure. A difference of $10 \mathrm{~mm} \mathrm{H}_{2} \mathrm{O}$ above or below the intended pressure setting is not considered a failure because it can be difficult to interpret a misaligned $\mathrm{x}$-ray film. Twenty percent (120 of 601) of the $x$-ray film-controlled reprogrammings differed from the intended setting by $20 \mathrm{~mm}$ $\mathrm{H}_{2} \mathrm{O}$ or more and were termed failures. Of these, 37 were corrected by a second readjustment, 26 by two further readjustments, and four by four further readjustments. In 22 cases the opening pressure was not corrected because the surgeon considered the settings to be close enough to the intended settings not to warrant further reprogrammings and x-ray films.

The reprogramming failure rate was $26.4 \%$ (14 of 53) in cases in which the valves were placed without a prechamber compared with 19.3\% (106 of 548) of those implanted with a prechamber. Analysis of the failure rate within 14 days postimplantation, when postoperative swelling might complicate palpation or reprogramming, showed no difference when compared with later reprogrammings. There were also no 
significant differences between different age groups with regard to reprogrammimg failure rates. No increase in the failure rate was seen with repeated reprogramming, and apart from the valves being replaced because of difficulties in reprogramming, there was no clear clustering of failures in individual valves (the number of reprogrammings per valve correlated well with the number of failures per valve; $r$ $=0.585, \mathrm{p}>0.0001)$.

Reasons for Reprogramming. Reprogramming of the opening pressure was required in $39.1 \%$ of the patients due to underdrainage and in $35.4 \%$ due to overdrainage (Table 4 ). Fifty-nine of the reprogrammings were planned (for instance, to lower, over a period of time, the intracranial pressure step by step after removal of a shunt ligature or to anticipate and avoid expected future complications of overdrainage). In 32 cases reprogramming was performed to correct an accidental resetting, in 92 to correct a previous reprogramming failure, and in 28 in connection with shunt ligation. Other reasons included raising the opening pressure to assess shunt independence prior to shunt removal requested by the patient; before ventricular endoscopy; preceding an extirpation of a meningioma; or to fine-tune the setting when the previous reprogrammed pressure setting differed from the intended setting by $10 \mathrm{~mm}$ $\mathrm{H}_{2} \mathrm{O}$.

\begin{tabular}{|cc|}
\hline \multicolumn{2}{|c|}{ TABLE 4 } \\
SUMMMRY OF INDICATIONS FOR PRESSURE YALYE \\
RE PROGRAMMING
\end{tabular}

Reprogramming Assessment. After the valve pressure was reprogrammed, the patient's status improved in $64.6 \%$ of assessable reprogrammings, in $74 \%$ of planned reprogrammings, and in $61 \%$ of the cases in which clinical symptoms or signs were the basis for the decision to readjust the pressure setting compared with $66.4 \%$ of the cases in which the decision was based on CT or MR studies.

Accidental Resetting. In 35 cases MR imaging caused the valve's opening pressure to be reset by at least $20 \mathrm{~mm} \mathrm{H}_{2} \mathrm{O}$, increasing it in seven and decreasing it in 28 cases (Fig. 5). In most cases this accidental resetting was corrected but not if the change was considered clinically insignificant. Data collected from records of patients whose valves were implanted in 1997 and thereafter indicated that MR imaging caused a resetting of the pressure valve in $11(26.8 \%)$ of 41 cases. 


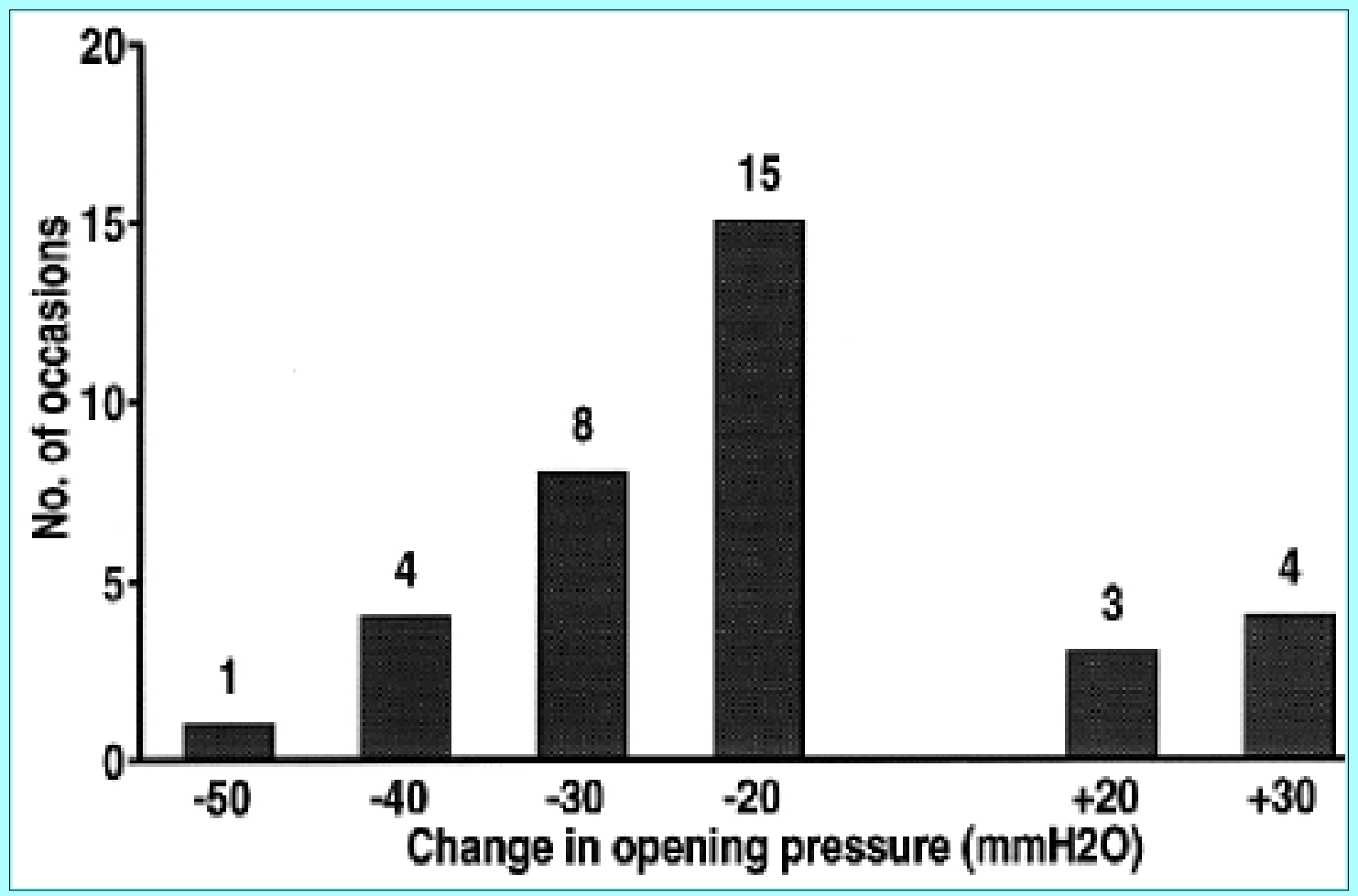

Fig. 5. Bar graph showing the magnitude and direction of change of the opening pressure caused by MR imaging in 35 cases.

On two occasions, 6 months apart, the pressure setting in one valve changed to an opening pressure of $110 \mathrm{~mm} \mathrm{H}_{2} \mathrm{O}$ (from $150 \mathrm{~mm} \mathrm{H}_{2} \mathrm{O}$ and $140 \mathrm{~mm} \mathrm{H}_{2} \mathrm{O}$ ). The neurosurgeon's note stated that the most probable cause was that the boy had played with a magnet designated for cleaning a fish aquarium, placing and twisting it against the skin covering the valve. Another patient, with tumoral hydrocephalus, had purchased a "magnetic pillow" that he had been convinced would help cure his disease. In using the pillow his valve's opening pressure altered from 90 to $50 \mathrm{~mm} \mathrm{H}_{2} \mathrm{O}$. The setting in a third valve was on two occasions lowered to $160 \mathrm{~mm} \mathrm{H}_{2} \mathrm{O}$ (from $180 \mathrm{~mm} \mathrm{H}_{2} \mathrm{O}$ and $200 \mathrm{~mm} \mathrm{H}_{2} \mathrm{O}$ ), for which no explanation could be found.

\section{Complication Rates}

Overall $21.5 \%$ (104) of all patients underwent shunt revision at least once. Of those patients in whom a first-time shunt placement procedure had been performed, the incidence of those not undergoing revision after 1 year was $74.6 \%$ (86 of 338); after 2 years, 67.9\% (79 of 246); after 3 years, 65.8\% (65 of 190); after 4 years, $56.5 \%$ (50 of 115); and after 5 years, 53.1\% (38 of 81). Patients who died were included in the retrospective analysis if their follow-up period was sufficient (Fig. 6). 


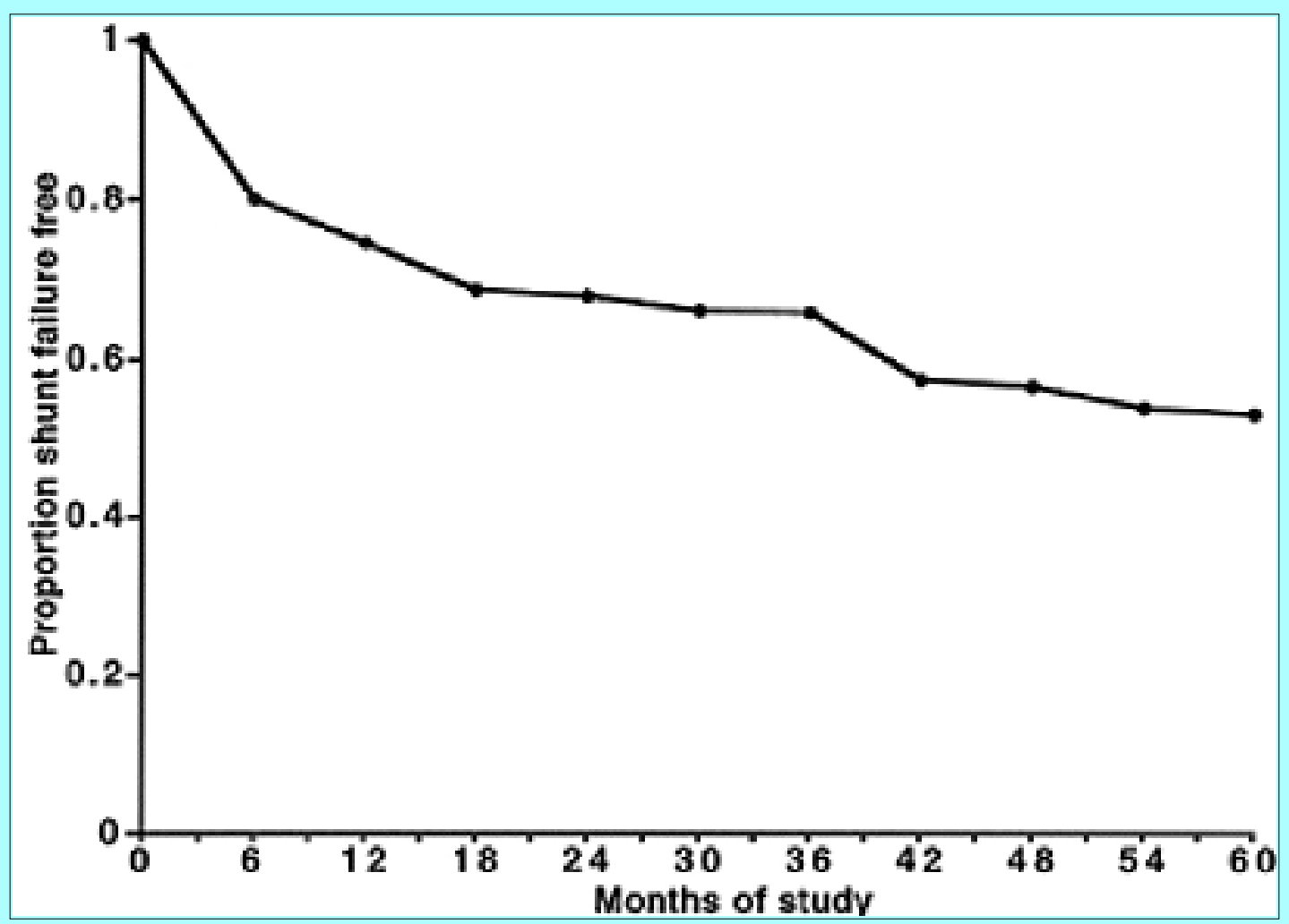

Fig. 6. Graph depicting the survival curve for patients who underwent a first-time shunt implantation procedure. Patients who died were included if their follow-up period was sufficient.

Of all 318 shunt revisions, $31.8 \%$ were related to the proximal catheter, $22.4 \%$ to the distal catheter, and $5.3 \%$ to the valve (Table 5). 


\begin{tabular}{|c|c|c|}
\hline \multicolumn{3}{|c|}{$\begin{array}{c}\text { TABLE } 5 \\
\text { SUMMARY OF REASONS FOR SHUNT REVSION* }\end{array}$} \\
\hline Type of Complication & No. of Cases & $\begin{array}{c}\text { Percentage of all } \\
\text { Complicalions }\end{array}$ \\
\hline proximal catheter & & 31.8 \\
\hline obstruction & 37 & \\
\hline $\begin{array}{l}\text { asconnecton } \\
\text { suboptimum position }\end{array}$ & 35 & \\
\hline CSF leakage & 9 & \\
\hline additional catheter insertion & 13 & \\
\hline val we related & 17 & 5.3 \\
\hline atrial catheter & & 3.5 \\
\hline obstruction & 5 & \\
\hline disconnection & 1 & \\
\hline suboptimum position & 5 & \\
\hline peritoneal cathe ter & & 18.9 \\
\hline obstuction & 19 & \\
\hline disconnection & 8 & \\
\hline suboptimum position & 33 & \\
\hline val we or peritoneal catheter obstuction & 3 & 0.9 \\
\hline subdural fluid collection & 38 & 11.9 \\
\hline infection & 56 & 17.6 \\
\hline suspected infection & 8 & 2.5 \\
\hline miscellaneous & 24 & 7.5 \\
\hline total & 318 & \\
\hline
\end{tabular}

Reasons for Removing a Codman Hakim Programmable Valve. In 90 cases it was necessary to remove the programmable valve, most often because of true or suspected shunt-related infection (Table 6). A valve-related complication was the cause of shunt malfunction in $2 \%$ [13] of all the implanted valves. Eleven were removed at shunt revision after pressure measurements obtained by means of a water column indicated the opening pressure was higher than the valve setting. Three of these could be explained by blockage because protein clots were visible in the valve housing, two were considered blocked because the abdominal catheter also showed increased resistance to flow, but in the remaining six there were no indications in the patient records as to the cause. One valve, removed after pressure measurement, was shown to have opened at too low an opening pressure $\left(80 \mathrm{~mm} \mathrm{H}_{2} \mathrm{O}\right.$ instead of the 100 $\mathrm{mm} \mathrm{H}_{2} \mathrm{O}$ at which it was set), and another because its distal connector fractured. At revision an additional three shunt systems were suspected of being blocked but could be flushed open and were left in place. 


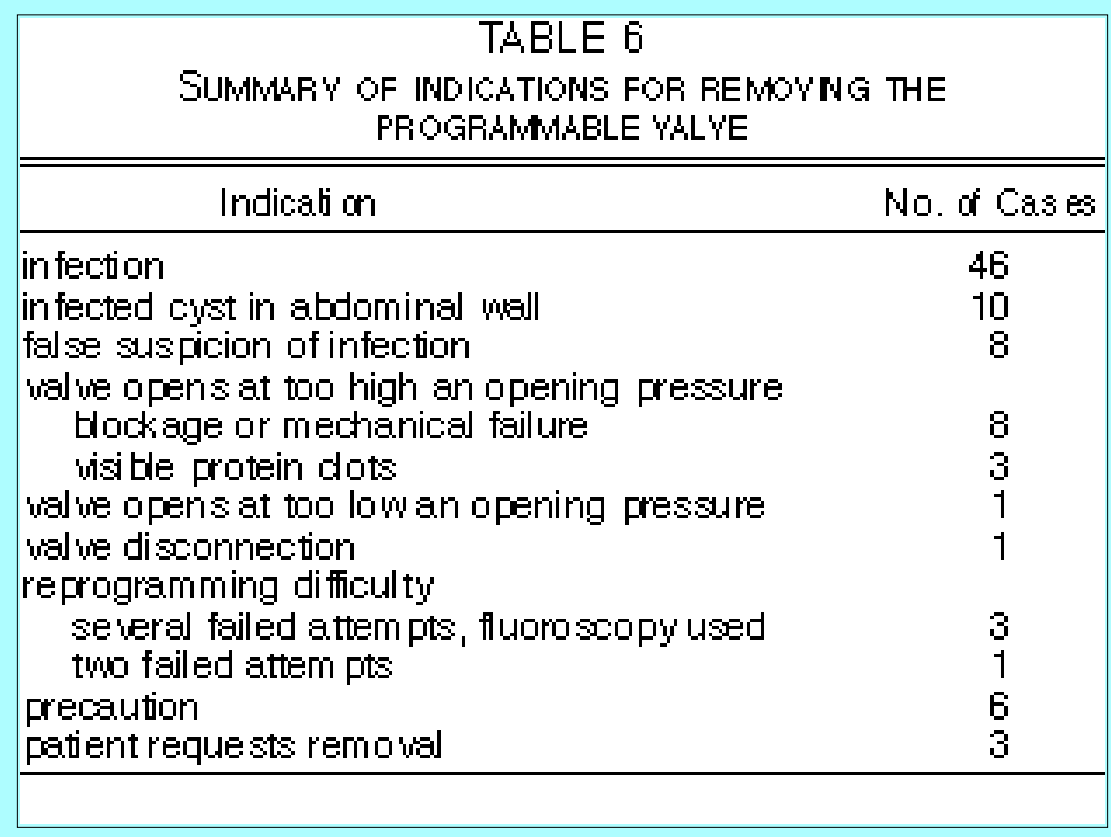

During six shunt revision procedures, the surgeon did not want to take the risk of leaving a possibly problematic valve in place and, as a precaution, exchanged the valve for one of the following reasons: no other reason for shunt malfunction could be detected (two cases), possible partial obstruction because the peritoneal catheter had been blocked (two cases), or possible contamination (two cases). On further examination (bench test) none of these six removed valves was shown to be dysfunctional.

Difficulty in reprogramming the pressure setting was the reason for removal of four valves: at revision one was found to be inverted (rotated 180š along its axis), two could not be adjusted despite repeated attempts by using fluoroscopy (one was placed in the lumbar region), and one was exchanged after only two attempts at reprogramming. One other valve, placed in the lumbar region, was ligated and left in place after two failed attempts at reprogramming.

All infected shunts or those suspected of being infected based on clinical examination were removed. The overall infection rate was $8.5 \%$ (56 of 660 cases). Ten of these harbor a liquid-filled cyst in the abdominal wall as the only symptom of shunt infection. For those patients who underwent shunt implantations for the first time, the infection rate was $6.6 \%$ overall and $5.6 \%$ when perioperative antibiotics had been given.

Three patients requested that their shunts be removed. Two of these patients and 10 others whose valves were removed because of infection turned out to be to be shunt independent.

Subdural Hematoma. A nontraumatic subdural fluid collection was demonstrated in 30 patients (5.1\%), subdural hematoma in 21 cases (19 adults and two children), and hygroma in nine cases (six adults and three children). Traumatic subdural hematomas were detected in eight patients (seven adults and one child). One infant developed an epidural hematoma. Of those patients with nontraumatic hematomas, six were treated in the traditional manner with surgical drainage of the fluid collection and ligation of the shunt system; in three surgical drainage was performed, but instead of ligation the opening pressure was raised; and in one ligation only was performed. Nine subdural hematomas (in eight adults and one child) and four hygromas (in three adults and one child) were treated by raising the valve's opening pressure alone; no surgery was necessary. Seven patients required no treatment.

\section{Patient Outcomes}


Outcome data for the different diagnosis groups are summarized in Table 7. In children outcome was excellent in $57.8 \%$, good in $39.3 \%$, and unchanged in 1.5\%. In adults outcome was excellent in $37.7 \%$, good in $52.7 \%$, and unchanged in $9.3 \%$. Of children less than 2 years of age, $96.2 \%$ improved, and of patients over 80 years of age $76.1 \%$ improved. Outcome was classified as worse in three patients because of progression of their underlying disease (anoxic brain damage, fungal meningitis, and traumatic subdural hematoma). One hundred seventeen patients (18 children and 99 adults), including the three aforementioned patients, died either of progression of their primary disease or of causes not related to shunt malfunction or infection. One infant suffering from intraventricular hemorrhage died shortly after shunt removal due to shunt-related infection.

\begin{tabular}{|c|c|c|c|c|}
\hline SUMMARY & $\begin{array}{r}\text { TA } \\
\text { NT OUT }\end{array}$ & GROUPED B & AGNOS B & \\
\hline & & Out & & \\
\hline Diagnosis & Worse & Unctanged & Good & Excell ent \\
\hline $\begin{array}{l}m \text { yelom eningocele } \\
\text { Dandy-unalker cyst }\end{array}$ & & & $\begin{array}{l}37.8 \% \\
57.1 \%\end{array}$ & $\begin{array}{l}62.2 \% \\
42.9 \%\end{array}$ \\
\hline congenital, miscellaneous & & $14.3 \%$ & $50.0 \%$ & $35.7 \%$ \\
\hline aqueductal stenosis & $2.7 \%$ & & $29.7 \%$ & $67.6 \%$ \\
\hline tumor & & $1.8 \%$ & $59.6 \%$ & $38.6 \%$ \\
\hline acquired, miscellane ous & $5.6 \%$ & $5.6 \%$ & $33.3 \%$ & $55.6 \%$ \\
\hline $\begin{array}{l}\text { infection, m iscellaneous } \\
\text { meningitis }\end{array}$ & & $18.2 \%$ & $\begin{array}{l}36.4 \% \\
21.4 \%\end{array}$ & $\begin{array}{l}45.5 \% \\
78.6 \%\end{array}$ \\
\hline trauma & & $29.4 \%$ & $64.7 \%$ & $5.9 \%$ \\
\hline in tracranial hem orrhage & & & & \\
\hline in trawentricular & & & $44.0 \%$ & $56.0 \%$ \\
\hline subarachnoid & & $3.6 \%$ & $64.3 \%$ & $32.1 \%$ \\
\hline miscellaneous & & & $91.7 \%$ & $8.3 \%$ \\
\hline NPH & & $12.5 \%$ & $57.0 \%$ & $30.5 \%$ \\
\hline arachnoidal cyst & & $8.3 \%$ & $25.0 \%$ & $66.7 \%$ \\
\hline pseudotumor ceretri & & $7.1 \%$ & $28.6 \%$ & $64.3 \%$ \\
\hline
\end{tabular}

\section{DISCUSSION}

Since Nulsen and Spitz[26] implanted the first pressure-responsive valve in 1949, a multitude of different valves have been developed. The majority of these are availabe with a fixed low-, medium- or high-pressure setting only. Mismatching the shunt valve's opening pressure with the patient's intracranial hydrodynamics is one of the factors that gives rise to over- or underdrainage of CSF. In theory, a transcutaneously adjustable valve should be better equipped to meet the demands imposed by changing conditions. Therefore, an adjustable valve improves the management of shunt-dependent patients because it enables noninvasive management of many of the complications and symptoms caused by such mismatching. Changing conditions in childhood, such as closing sutures and attainment of the erect posture, as well as in older patients with clinical symptoms or radiological findings of NPH, should benefit from a pressure-adjustable valve.

Other authors indicate the programmable valve to be of value in the treatment of NPH, hydrocephalus developing after a subarachnoid hemorrhage, arachnoid cyst, cysts in general, aqueductal stenosis, and overdrainage of CSF.[3,4,16,24,28,31,32] Infants, children, and bedridden patients also benefit, as do patients who have undergone many previous surgical revisions of their shunt system.[3,28,29,30,35]

\section{Shunt Implantation}


To minimize the risk of introducing larger foreign particles, the valve should not be filled or flushed with any solution prior to implantation. It should be placed firmly against the skull bone, and care must be taken to ensure the valve is not rotated. For small children with an occipital burr hole, the pediatric version of the valve, without a prechamber, is indicated to allow retroauricular positioning. Before introduction of the pediatric valve version, we shortened the valve in some cases by cutting off the prechamber. The placement of the Codman Hakim programmable valve in premature patients and infants was not shown to be problematic, and no shunt revisions due to skin tension were performed. A postimplantation $x$-ray film need not be obtained if the valve setting is inspected before implantation by use of a magnifying glass.

\section{Valve Pressure Programming}

Opening Pressure at Implantation. In newborn infants the opening pressure at implantation should be set low and increased thereafter, usually within the first 2 months. To avoid subdural hematomas in older patients, we initally establish a high opening pressure and decrease it step by step when necessary.

Pressure Reprogramming. The magnitude of single reprogrammings was generally not larger than 30 or $40 \mathrm{~mm} \mathrm{H}_{2} \mathrm{O}$ because a larger adjustment can be risky. The ability to change the opening pressure in smaller consecutive steps allows for adaptation and evaluation. Furthermore, fine tuning or titrating the opening pressure more precisely than the traditional low-, medium-, or high-pressure settings offered by nonprogrammable valves optimizes treatment; this has also been reported by other authors. $[15,33]$ Retrospectively, we estimate that in at least one third of patients in whom pressure adjustments were made, valve exchange would have been necessary if nonprogrammable valves had routinely been used.

In $58 \%$ of the cases reprogramming adjustments were not required. Several factors might explain this: 1) an optimum opening pressure was achieved at implantation, 2) fine adjustment was not attempted despite minor symptoms of over- or underdrainage, or 3) insufficient follow-up data were obtained.

Data regarding the number of episodes of pressure reprogrammings per patient, the percentage of patients whose valves were reprogrammed at least once, and the magnitude of the change in opening pressure between implantation and follow up, provide an indication of whether the programmable valve was of value or not. Although the insignificant differences among groups makes it difficult to propose guidelines as to which patients should receive a programmable valve, the following benefits are worth pointing out: 1) the capability to adjust the opening pressure was more frequently used in the younger age groups and in patients whose initial programmable valve was implanted at shunt revision; 2) the uncertainty in defining the optimum opening pressure at implantation for patients with NPH $[5,19,23]$ is overcome by the use of a programmable valve; 3) CT-guided, planned lowering of the pressure in arachnoid cysts, Dandy-Walker syndrome cysts, and long-standing hydrocephalus (such as aqueductal stenosis) allows the brain parenchyma to adjust over a longer time period, thereby minimizing the risk of overdrainage-related complications; and 4) reprogramming of the valve opening pressure in patients with pseudotumor cerebri is guided by examination of the optic fundus.

In our study in nine patients of varying diagnoses, repeated fine adjustments (defined as more than 10 reprogrammings) did not significantly improve outcome.

The ball and cone construction of the valve does lead to an increased flow rate in the vertical body position because of the siphon effect.[1,6,7,9,34] A siphon-reducing device is an option, and in selected 
patients outcome could perhaps be further improved by implanting such a device. The majority of our patients in whom overdrainage occurred were managed by raising the opening pressure.

Plain radiography of the skull or fluorosopy[17] should be used to check the valve's setting after every reprogramming adjustment is made. Although it is a time-consuming inconvenience for the patient, it is clearly acceptable given that surgical revision of the shunt might be the only alternative. A more accurate reading of a valve's setting on a plain skull x-ray film can be achieved by drawing one line on the film along the axis of the valve and a second line from the center of the the stepped cam through the opening pressure indicator. The angle between these two lines indicates the current setting.

Failure of Valve Pressure. Possible causes of reprogramming failure are: 1) difficulty in accurately localizing the position of the inlet valve or 2) removal of the programming unit's transmitter too early. Having a sample valve (or valve model) at hand is of help in palpating the position of the inlet valve. Adequate instructions and training are essential. Another reason that reprogramming the valve setting can fail is rotation of the valve along its axis; however, a high degree of offset between transmitter and valve is tolerated.[1,27] Even an inverted valve can be reprogrammed. Retroauricular implantation, in which the valve can rest firmly against the skull bone, provides the best positioning by making palpation easier and hindering rotation. Moreover, it is important to record whether the implanted valve was one with or without a prechamber (extra care should be taken when reprogramming a valve without a prechamber) and to keep accurate records of reprogramming adjustments and the x-ray film control readings. A patient follow-up card, on which all valve settings are noted, facilitates management in an acute situation of shunt malfunction.

In our experience the durability of the valve's reprogramming mechanism was clearly satisfactory, and its function was accurate long after implantation and repeated pressure adjustments.

Reprogramming Assessment. Following a planned strategy for each individual patient improves reprogramming outcome.

Accidental Resetting. In our experience, as well as that of others, [1,3,7,25,27,29] the valve's opening pressure must always either be checked after MR imaging or routinely reprogrammed after MR imaging followed by obtaining a control x-ray film. An external magnetic field other than MR imaging can alter the pressure setting; however, in our 7-year experience only two cases of such an event were confirmed (those that involved a magnetic pillow and an aquarium magnet). Alteration of the valve's opening pressure setting by other magnets and magnetic fields encountered in every day life (for example, earphones, refrigerator magnets, wireless telephones, loudspeakers, and airport metal detectors) were not observed.

\section{Shunt-Related Complications}

Of those patients who underwent a first-time shunt implantation, $21.5 \%$ subsequently underwent surgical revision of the system. The majority of revisions were necessitated by catheter-related complications and shunt-related infections.

Valve-Related Complications. The Codman Hakim programmable valve has been shown to conform accurately to the manufacturer's specifications, $[1,7,35]$ and it has a comparatively low sensitivity to elevated protein levels in the CSF.[35] The valve itself was the site or cause of shunt malfunction in only $13(2 \%)$ of the 660 implanted programmable valves, which compares well with the best results obtained using other types of valves.[10] Placement of a lumboperitoneal shunt in which the Codman Hakim 
programmable valve is used should, in our opinion, be avoided because of reprogramming difficulty. An inverted valve can be identified on a plain skull x-ray film and reprogrammed following a specific procedure. No shunt revisions were required due to valve migration despite the cylindrical shape of the valve.

Subdural Hematoma and Reprogramming. The ability to treat a shunt-related complication, such as a subdural fluid collection, by reprogramming the valve to a higher setting is an advantage over nonprogrammable valves, and it enables the opening pressure to be slowly lowered once the fluid collection is resorbed. Our findings correspond with those obtained in the treatment of subdural hematomas, $[3,15,33]$ hygromas, $[1,29]$ or both[20,32] by raising the opening pressure alone, without having to ligate the shunt. The treatment of subdural fluid collections by surgical drainage and ligation of the shunt while at the same time reprogramming the valve has also been reported elsewhere. $[4,8,29,31,32]$

\section{CONCLUSIONS}

Catheter-related complications and shunt-related infections were the main reasons for surgical revision and the major cause of shunt failure.

We believe the aforementioned programming strategies, based on our experience and theoretical approaches to the individual patient's profile, will help to avoid complications and improve patient outcome.

The indications for a programmable valve are not easy to define. It is difficult, if not impossible, to know at implantation in which patients an opening pressure adjustment will be required. A programmable valve has the clear advantage of enabling the surgeon to make transcutaneous alterations of the valve's opening pressure as the patient's clinical course changes during the postoperative period; in addition, it allows for the improved management of shunted-dependent patients of all ages and with various diagnoses. Because we never in advance know which patient will turn out to be a complicated case, our preference is, therefore, to use a programmable valve in all conditions.

\section{Disclosure}

The authors have no financial interest in the CFS shunt valve discussed in this report.

\section{References}

1. Aschoff A, Kremer P, Benesch C, et al: Overdrainage and shunt technology. A critical comparison of programmable, hydrostatic and variable-resistance valves and flow-reducing devices. Childs Nerv Syst 11:193-202, 1995

2. Barnett GH, Hahn JF, Palmer J: Normal pressure hydrocephalus in children and young adults. Neurosurgery 20:904-907, 1987

3. Belliard H, Roux FX, Turak B, et al: [The Codman Medos programmable shunt valve. Evaluation of 53 implantations in 50 patients.] Neurochirurgie 42:139-146, 1996 (Fr)

4. Black PM, Hakim R, Bailey NO: The use of the Codman-Medos programmable Hakim valve in the management of patients with hydrocephalus: illustrative cases. Neurosurgery 34:1110-1113, 1994 
5. Boon AJW, Tans JTJ, Delwel EJ, et al: Dutch Normal-Pressure Hydrocephalus Study: randomized comparison of low- and medium-pressure shunts. J Neurosurg 88:490-495, 1998

6. Czosnyka Z, Czosnyka M, Richards H, et al: Hydrodynamic properties of hydrocephalus shunts. Acta Neurochir Suppl 71:334-339, 1998

7. Czosnyka Z, Czosnyka M, Richards HK, et al: Posture-related overdrainage: comparison of the performance of 10 hydrocephalus shunts in vitro. Neurosurgery 42:327-334, 1998

8. Dietrich U, Lumenta C, Sprick C, et al: Subdural hematoma in a case of hydrocephalus and macrocrania. Experience with a pressure-adjustable valve. Childs Nerv Syst 3:242-244, 1987

9. Drake JM, Kestle JRW, Milner R, et al: Randomized trial of cerebrospinal fluid shunt valve design in pediatric hydrocephalus. Neurosurgery 43:294-305, 1998

10. Drake JM, Tenti G, Sivalsganathan S: Computer modeling of siphoning for CSF shunt design evaluation. Pediatr Neurosurg 21:6-15, 1994

11. Faulhauer K, Schmitz P: Overdrainage phenomena in shunt treated hydrocephalus. Acta Neurochir 45:89-101, 1978

12. Hakim S: Hydraulic and mechanical mis-matching of valve shunts used in the treatment of hydrocephalus: the need for a servo-valve shunt. Dev Med Child Neurol 15:646-653, 1973

13. Hakim S: The Physics and Pathophysiology of the Hydraulic Complex of the Central Nervous System. The Mechanics of Hydrocephalus and Normal Pressure Hydrocephalus. Thesis. Cambridge, MA: Massachusetts Institute of Technology, 1985

14. Hakim S, Duran de la Roche F, Burton JD: A critical analysis of valve shunts used in the treatment of hydrocephalus. Dev Med Child Neurol 15:230-255, 1973

15. Kamano S, Nakano Y, Imanishi T, et al: Management with a programmable pressure valve of subdural hematomas caused by a ventriculoperitoneal shunt: case report. Surg Neurol 35:381-383, 1991

16. Kamiryo T, Fujii Y, Kusaka M, et al: Intracranial pressure monitoring using a programmable pressure valve and a telemetric intracranial pressure sensor in a case of slit ventricle syndrome after multiple shunt revisions. Childs Nerv Syst 7:233-234, 1991

17. Kaufman BA, Moran CJ, Schlesinger J: Fluoroscopy of programmable cerebrospinal fluid shunt valve settings. Technical illustration. J Neurosurg 86:735, 1997

18. Kuurne T, Servo A, Porras M: Subdural effusions re-appearing after shunts in patients with nontumoural stenosis of the aqueduct. Acta Neurochir 67:127-234, 1983

19. Larsson A, Jensen C, Bilting M, et al: Does the shunt opening pressure influence the effect of shunt surgery in normal pressure hydrocephalus? Acta Neurochir 117:15-22, 1992

20. Lumenta CB, Roosen N, Dietrich U: Clinical experience with a pressure-adjustable valve SOPHY in the management of hydrocephalus. Childs Nerv Syst 6:270-274, 1990

21. Matsumae M, Sato O, Itoh K, et al: Quantification of cerebrospinal fluid shunt flow rates.

Assessment of the programmable pressure valve. Childs Nerv Syst 5:356-360, 1989 
22. McCullough DC: Symptomatic progressive ventriculomegaly in hydrocephalics with patent shunts and antisiphon devices. Neurosurgery 19:617-621, 1986

23. McQuarrie IG, Saint-Louis L, Scherer PB: Treatment of normal pressure hydrocephalus with low versus medium pressure cerebrospinal fluid shunts. Neurosurgery 15:484-448, 1984

24. Miyake H, Ohta T, Kajimoto Y, et al: A new ventriculoperitoneal shunt with a telemetric intracranial pressure sensor: clinical experience in 94 patients with hydrocephalus. Neurosurgery 40:931-935, 1997

25. Mursch K, Behnke J, Christen HJ, et al: Use of transcranial real-time ultrasonography for programming a shunt valve system. Childs Nerv Syst 12:392-395, 1996

26. Nulsen FE, Spitz EB: Treatment of hydrocephalus by direct shunt from ventricle to jugular vein. Surg Forum 2:399-403, 1952

27. Ortler M, Kostron H, Felber S: Transcutaneous pressure-adjustable valves and magnetic resonance imaging: an ex vivo examination of the Codman-Medos programmable valve and the Sophy adjustable pressure valve. Neurosurgery 40:1050-1058, 1997

28. Reinprecht A, Czech T, Dietrich W: Clinical experience with a new pressure-adjustable shunt valve. Acta Neurochir 134:119-124, 1995

29. Reinprecht A, Dietrich W, Bertalanffy A, et al: The Medos Hakim programmable valve in the treatment of pediatric hydrocephalus. Childs Nerv Syst 13:588-594, 1997

30. Rohde V, Mayfrank L, Ramakers VT, et al: Four-year experience with the routine use of the programmable Hakim valve in the management of children with hydrocephalus. Acta Neurochir 140:1127-1134, 1998

31. Schmitt J, Spring A: [Therapy of normal pressure hydrocephalus with the transcutaneously magnetically adjustable shunt.] Neurochirurgia 33 (Suppl 1):23-26, 1990 (Ger)

32. Sindou M, Guyotat-Pelissou I, Chidiac A, et al: Transcutaneous pressure adjustable valve for the treatment of hydrocephalus and arachnoid cysts in adults. Experience with 75 cases. Acta Neurochir 121:135-139, 1993

33. Sutcliffe JC, Battersby RD: Do we need variable pressure shunts? Br J Neurosurg 6:67-70, 1992

34. Trost HA: Is there a reasonable differential indication for different hydrocephalus shunt systems? Childs Nerv Syst 11:189-192, 1995

35. Trost HA, Heissler HE, Claussen G, et al: Testing the hydrocephalus shunt valve: long-term bench test results of various new and explanted valves. The need for model for testing valves under physiological conditions. Eur J Pediatr Surg 1 (Suppl 1):38-40, 1991

36. Walsh JW, James HE: Subtemporal craniectomy and elevation of shunt valve opening pressure in the management of small ventricle-induced cerebrospinal fluid shunt dysfunction. Neurosurgery 10:698-703, 1982

Manuscript received September 10, 1999. 
Accepted in final form September 27, 1999.

This work was supported by the Herman Groos Foundation, Elsa Schmitz' Foundation, and the Skane County Council's Research Development Foundation.

Address reprint requests to: Bertil Romner, M.D., Ph.D., Department of Neurosurgery, Division of Neurological Sciences, Lund University Hospital, 22185 Lund, Sweden. email:

bertil.romner@neurokir.lu.se. 